3 Arcand G, Girard F, McCormack M, Chouinard P, Boudreault D, Williams $S$. Bilateral sixth cranial nerve palsy after unintentional dural puncture. Can J Anesth 2004; 51: 821-3.

4 Bechard P, Perron G, Larochelle D, Lacroix $M$, Labourdette A, Dolbec P. Case report: epidural blood patch in the treatment of abducens palsy after a dural puncture. Can J Anesth 2007; 54: 146-50.

\section{Not all apples look alike}

To the Editor:

In the paper by Alison Froese, ${ }^{1}$ some statements are made regarding shortages of health professionals in developing countries. The phrase "Severe shortages of trained health professionals plague developing countries” unfortunately gives an erroneous impression about the current situation in many of the, so called, developing countries.

South America, one of the continents mentioned in the abstract, is a good example. Of course, countries in this area have grown and at various speeds, due to very complex political and economic situations. Some of the countries have developed at a faster rate, but are still regarded as developing countries.

Anesthesia, as a specialty, has grown in accordance with the economic development of each country. In Argentina, Brazil, Colombia, Chile, and Uruguay, anesthesia is a mature specialty, as evidenced by use of modern equipment and advanced monitoring technology, access to current drugs, scientific societies with numerous activities, on line journals, and a variety of good quality research (in Chile for example) published in indexed, scientific journals. More importantly, anesthesiologists are fully trained, with high standards and are accredited and certified by the government or by local scientific societies.

I understand the concepts described by Dr. Froese, but her use of the term "developing countries" can be misleading. There is a thin line between developing and underdeveloped countries that is not always clearly visible. Along the same line of reasoning, not all developing countries are alike.

Guillermo Lema MD

Past President, Chilean Society of Anaesthesia

Professor

Pontificia Universidad Católica de Chile, Santiago,

Chile

E-mail: glema@med.puc.cl

Accepted for publication January 10, 2008.

\section{Reference}

1 Froese $A$. Anesthesia and the role of short-term service delivery in developing countries. Can J Anesth 2007; 54: 940-6.

\section{Reply:}

Dr. Lema has very aptly identified the pitfalls of illdefined, blanket terms such as 'developing countries'. I appreciate the very useful, specific information he has provided on the mature status of the specialty of anesthesia in several countries within South America. I regret any misconceptions that may have arisen from the terminology I used in my article. Not surprisingly, a scan of the schedule of one organization that works extensively in Central and South America revealed not a single project planned for any of the five countries mentioned by Dr. Lema. As Dr. Lema noted, complex political and economic factors make development occur at varying rates, even within a single continent, and the projects listed were all in other, less developed countries within South America. It will be a great day when anesthesia and surgical services, of the quality described by Dr. Lema, become available to all people everywhere. Meanwhile, there is still much we can contribute along the way.

Alison Froese MD

Kingston General Hospital, Queen's University, Kingston, Canada

E-mail: froesea@kgh.kari.net 